\title{
Bio-Synthesis and Characterisation of Cuo Nanoparticles using Aloe Barbadensis
}

\author{
Arjun kumar A. ${ }^{1}$, Swaroop B.S. ${ }^{2} \&$ Jithesh S Rai $^{3}$ \\ ${ }^{1-3}$ Students, Department of Chemical Engineering, MVJ College of Engineering, Bangalore, India.
}

\section{ABSTRACT}

In the present work, green synthesis of copper oxide nanoparticles has wide interest due to its inherent features such as eco-friendly and low costs Here we propose a cost effective and eco-friendly green synthesis of copper oxide nanoparticles using aloe barbadensis and copper acetate. Aloe barbadensis has antioxidant property that helps in the formation of nanoparticles. Aloe barbadensis extract was obtained by heating it in distilled water and mixed to copper acetate to form copper oxide nanoparticles. The synthesised nanoparticles were analysed using UV-Visible spectroscopy, X-ray diffraction studies (XRD) and Fourier-transform infrared spectroscopy (FTIR).

Keywords: Aloe barbadensis, Copper acetate, Copper oxide, Green synthesis, Nanoparticles.

\section{Introduction}

Nanotechnology plays a very important role in modern research, it is the most capable technology that can be applied in almost all fields such as pharmaceutical, electronics, health care, food and feed, biomedical science, drug and gene delivery, chemical industry, energy science, cosmetics, environmental health, mechanics and space industries. It has also been utilized for the treatments of infection, cancer, allergy, diabetes and inflammation. Green chemistry is an implementation, development, design of chemical [1].

Synthesis of nanoparticles (NPs) can be performed using a number of customarily used chemical and physical methods. Physical and green NPs synthesis methods have been developed and utilized to fabricate numerous NPs. However, green synthesis techniques are considered as one step, economic and eco-friendly method due to using natural bio reductants and stabilizers in the formation of the NPs [2,3]. Metal oxide nanoparticles are generally synthesised because of their optical, electronic, magnetic and catalytic properties. Metal oxides are preferred for surface coatings, production of microelectronic circuits, sensors, piezoelectric devices, and fuel cells. In addition, most of the catalysts used for the industrial operations contain an oxide as active phase, promoter or support [4].

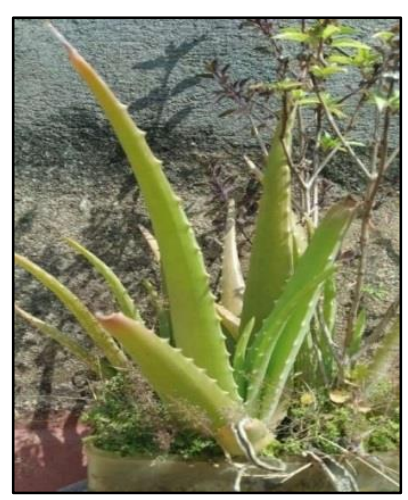

Fig.1 Aloe barbadensis

In the current research, the green synthesis of nanomaterials using various parts of plant extracts is a growing field in Nanoscience, with accent to avoid the usage of toxic chemicals. In the green synthesis method, the plant extract used for synthesis of nanoparticles act as reducing and capping agent [5]. Aloe barbadensis contains 200 potentially 
active constituents: vitamins, enzymes, minerals, sugars, lignin, saponins, salicylic acids and amino acids, which are responsible for the multifunctional activity of Aloe barbadensis. Vitamins: It contains Vitamins A (beta-carotene), $\mathrm{C}$ and $\mathrm{E}$, which are antioxidants [6]. In this biosynthesis, aqueous leaves extract of Aloe barbadensis used to synthesize copper oxide nanoparticles (CuO NPs) and thereby improving the importance of plant source and involving green chemistry for the synthesis of other NPs as future research.

\section{Literature Review}

Jale naktiyok's article "Synthesis of copper oxide $(\mathrm{CuO})$ from thermal decomposition of copper acetate monohydrate $\left(\mathrm{Cu}\left(\mathrm{CH}_{3} \mathrm{COO}\right) 2 . \mathrm{H}_{2} \mathrm{O}\right)$ " describes the synthesis of copper oxide $(\mathrm{CuO})$ via the thermal decomposition of copper (II) acetate monohydrate $\left(\mathrm{Cu}\left(\mathrm{CH}_{3} \mathrm{COO}\right) 2 . \mathrm{H}_{2} \mathrm{O}\right)$ in air atmosphere. The obtained products were characterised at three different temperatures by Xray diffraction (XRD), Fourier transform infrared spectroscopy (FTIR), Scanning electron microscopy (SEM) and Energy disperse spectroscopy (EDS) analysis [7]. Samar fatma, et al., explains a green nanotechnology to synthesise nanoparticles (NPs) in their research paper "green synthesis of copper nanoparticles from Passiflora foetida leaf extract and its antibacterial activity". In this paper, biosynthesis of stable copper $(\mathrm{Cu})$ NPs was done using Passiflora foetida leaf extract. It took 8 to 10 minutes to synthesise nanoparticles (NPs), so this method can be used for rapid and eco-friendly biosynthesis of stable CuNPs [8]. J. Santosh kumar, S. et al., emphasizes on synthesis of zinc oxide nanoparticles in "Synthesis of zinc oxide nanoparticles using plant leaf extract against urinary tract infection pathogen". Nanoparticles Were synthesized using Passiflora Caerulea fresh leaf extract and were characterized. This paper reveals an efficient, eco-friendly and simple method for the green synthesis of multifunctional ZnO NPs using P. Caerulea. Urinary tract infection Causing microbes were isolated from the disease affected patient urine sample. It indicates the biomedical capability of ZnO NPs [9].

\section{Methodology}

\subsection{Collection of Samples}

Aloe barbadensis healthy leaves were collected and rinsed with distilled water to remove the dirt particles from the surface of the leaves.

\subsection{Preparation of Aloe Barbadensis Leaf Extract}

The rinsed leaves were dried using tissue paper and were weighed, then dried in hot air oven at $50^{\circ} \mathrm{C}$ for 15 minutes to remove the moisture content. The dried leaves were weighed again and $20 \mathrm{~g}$ of the leaves were crushed in mortar and pistol. The crushed leaves were taken into a beaker containing $250 \mathrm{ml}$ of distilled water, then it was heated at 60

${ }^{\mathrm{O}} \mathrm{C}$ on a mantle for 45 minutes to obtain a yellowish extract. The extract was filtered using Whatmann filter paper to remove the solid particles and obtain the extract. The extract was stored in refrigerator for further use [10].

\subsection{Chemicals and Instruments}

The chemicals used were acetic acid, hydrogen peroxide, copper wire. Hot air oven was used to dry the leaves and distilled water was used to prepare extract solution. For characterization UV-Visible spectroscopy, X-ray diffraction studies (XRD) and Fourier-transform infrared spectroscopy (FTIR) were used. 


\subsection{Preparation of Copper Acetate Solution}

Acetic acid and hydrogen peroxide were mixed in equal proportion and heated till it boils, then the flame was switched off and copper wire was introduced into the solution carefully within few minutes the solution turned to blue in colour, that indicates the formation of copper acetate.

\subsection{Synthesis of Copper Oxide Nanoparticles}

The $\mathrm{CuO}$ NPs were synthesised by taking $10 \mathrm{ml}$ of the extract in a beaker and placing it on a magnetic stirrer at 50-60 degree Celsius and copper acetate was added to the extract till it turns to dark green colour. Then the sample was placed in a muffle furnace at 400 degree Celsius for 5 minutes to obtain solid particles of CuO NPs.

\subsection{Characterization}

The UV-Visible absorption spectra were recorded by the UV-Visible spectrophotometer. Chemical binding of synthesized nanoparticles was analyzed using a Fourier transform infrared (FTIR) spectrometer. X-ray diffraction studies were conducted to determine the solid particles present [11].

\section{Results and Discussions}

\subsection{UV-Visible Spectroscopy}

The UV-Visible spectroscopy analysis of copper oxide particles was conducted in the wavelength range of 200-600 $\mathrm{nm}$, due to inter band transition of core electrons of $\mathrm{CuO}$ NPs. The spectrum is represented in the figure 2 . The peak obtained at $342 \mathrm{~nm}$ confirms the presence of CuO NPs.

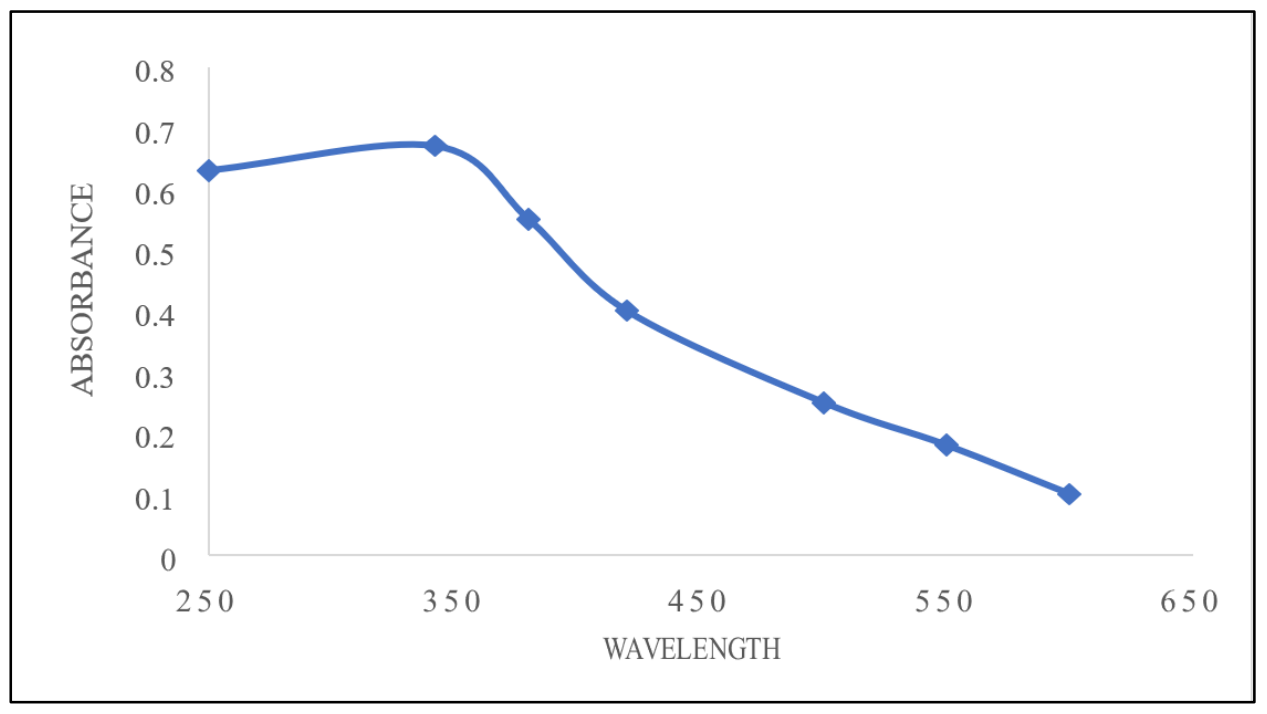

Fig.2 Plot of UV-visible spectroscopy

\subsection{X-Ray Diffraction Studies (XRD)}

The XRD spectra of synthesised nanoparticles were carried out using XRD for $2 \Theta$ values. the XRD pattern for the synthesizes nanoparticles is shown in the figure 3 . The $2 \Theta$ values at $15.0506,24.0393,28.3665,31.6216$, 33.7941,40.5360 and 68.3556 were observed. The XRD pattern of the CuO NPs is crystalline and identical to simple cubic. 


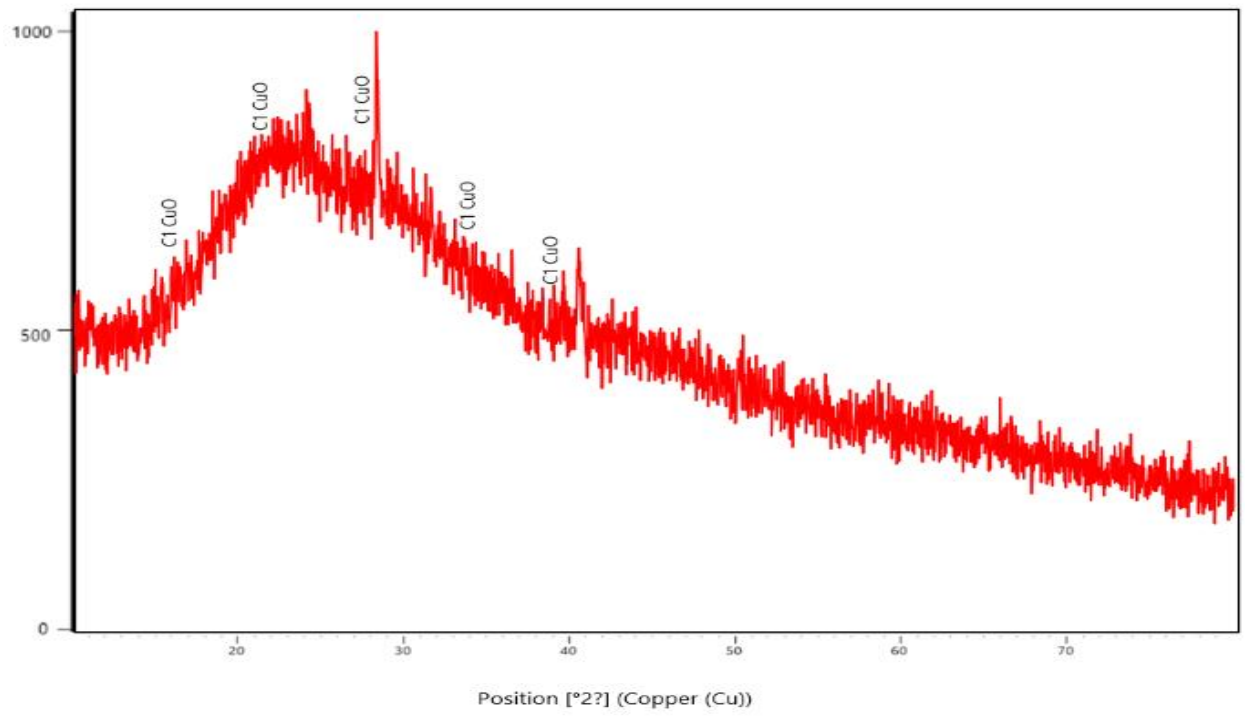

Fig.3 XRD profile of $\mathrm{CuO}$ nanoparticles

\subsection{Fourier-Transform Infrared Spectroscopy (FTIR)}

The FTIR spectra of copper oxide nanoparticles is shown in the figure 4. The spectra show medium absorption in the region of $3679.38,3487.52,2934.22,2373.76,1448.29,1100.79,867.94,533.79 \mathrm{~cm}-1$. Absorption at 533.79 $\mathrm{cm}^{-1}$ identifies the presence of $\mathrm{CuO}$ NPs.

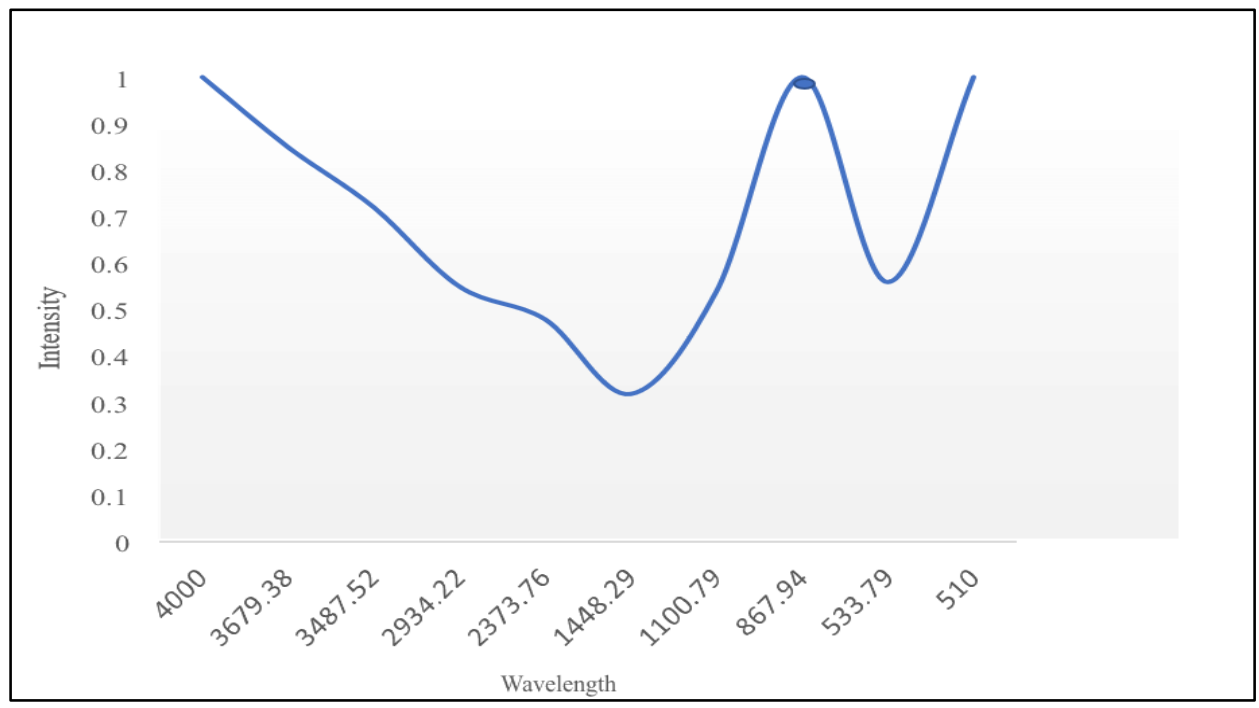

Fig.4 FTIR plot of $\mathrm{CuO}$ nanoparticles

\section{Conclusion}

This method is easily available starting from materials, inexpensive and procedure is easy to carry out at any laboratory, use of toxic reagent is avoided and pollution free, here we report eco-friendly synthesis of CuO NPs using a leaf extract of Aloe barbadensis. The UV-Vis spectra analysis shows that the absorption values for $\mathrm{CuO}$ NPs was at $342 \mathrm{~nm}$. In FTIR spectroscopic analysis there is sharp peak observed at $533 \mathrm{~cm}^{-1}$ which is the 
Asian Journal of Applied Science and Technology Volume 4, Issue 3, Pages 210-214, July-September 2020

characteristics of $\mathrm{Cu}-\mathrm{O}$ bond. The XRD analysis confirmed that the obtained NPs were crystalline and simple cubic.

\section{References}

[1] K. Saranyaadevi, V. Subha, R. S. Ernest Ravindran, S. Renganathan. "Synthesis and Characterization of Copper Nanoparticle using Capparis Zeylanica leaf Extract”. ChemTech, vol.10, 2014.

[2] Borna Fardsadegh, Hoda Jafarizadeh-Malmiri. "Aloe vera leaf extract mediated green synthesis of selenium nanoparticles and assessment of their In vitro antimicrobial activity against spoilage fungi and pathogenic bacteria strains”. Green processing and synthesis, Vol 8, 2019.

[3] Sadia Saif, Arifa Tahir, et al. "Plant Mediated Green Synthesis of CuO Nanoparticles: Comparison of Toxicity of Engineered and Plant Mediated CuO Nanoparticles towards Daphnia magna”. MDPI, Nanomaterials, 6, $205,2016$.

[4] Ashwini Anantharaman1, Liz George, Mary George. "green synthesis of copper oxide nanoparticles and its applications". IJARSE, Vol. No. 5, 2016.

[5] G. R. Abhiman, P. Sri Devi, K. A. Vijayalakshmi. "Green synthesis with antibacterial investigation of Copper nanoparticles using Azadirachta indica (neem) leaf extract”. IJSRST, Science and techno, Vol 4, 2018.

[6] Sanjit Kumar Kar and Tushar Kanti Bera. "phytochemical constituents of aloe vera and their multifunctional properties: a comprehensive review". IJPSR, 2018.

[7] Jale naktiyok, A. Kadir ozer. "Synthesis of copper oxide $(\mathrm{CuO})$ from thermal decomposition of copper acetate monohydrate $(\mathrm{Cu}(\mathrm{CH} 3 \mathrm{COO}) 2 . \mathrm{H} 2 \mathrm{O})$ ". Omer Halisdemir University Journal of Engineering Sciences, Volume 8, 1292-1298, 2019.

[8] Samar fatma, Kalainila p, Ernest ravindran, Renganathan s. "green synthesis of copper nanoparticles from Passiflora foetida leaf extract and its antibacterial activity". Asian journal of pharmaceutical and clinical research, Vol. 10, 2017.

[9] J. Santosh kumar, S. Venkat kumar, S. Rajesh kumar. "Synthesis of zinc oxide nanoparticles using plant leaf extract against urinary tract infection pathogen”. Elsevier, resource-efficient technologies, 2017.

[10] S. Ansilin, J. Kavya Nair, C. Aswathy, et al. "Green Synthesis and Characterisation of Copper Oxide Nanoparticles using Azadirachta indica (Neem) Leaf Aqueous Extract". Journal of Nanoscience and Technology 2(5), 221-223, 2016.

[11] Katrin Quester, M. Avalos Borja, et al. "Biosynthesis and microscopic study of metallic nanoparticles- A review". Elsevier, Micron, 2013.

[12] Lina Huang, Heqing Jiang, et al. "synthesis of nanoparticles containing diamond-like carbon films by electrochemical method". Electrochemistry communications 8(2):262266, 2006. 